\title{
Involvement of BDNF Signaling Transmission from Basolateral Amygdala to Infralimbic Prefrontal Cortex in Conditioned Taste Aversion Extinction
}

\author{
Jian Xin, ${ }^{1 *}$ Ling Ma, ${ }^{1,2 *}$ Tian-Yi Zhang, ${ }^{1}$ Hui Yu, ${ }^{1}$ Yue Wang, ${ }^{1}$ Liang Kong, ${ }^{1}$ and Zhe-Yu Chen ${ }^{1}$ \\ ${ }^{1}$ Department of Neurobiology, Shandong Provincial Key Laboratory of Mental Disorders, School of Medicine, Shandong University, Jinan, Shandong \\ 250012, P.R. China, and 2Department of Clinical Laboratory, Second Hospital of Shandong University, Jinan, Shandong 250033, P.R. China
}

\begin{abstract}
Brain-derived neurotrophic factor (BDNF) and its receptor, tropomyosin-related kinase receptor B (TrkB), play a critical role in memory extinction. However, the detailed role of BDNF in memory extinction on the basis of neural circuit has not been fully understood. Here, we aim to investigate the role of BDNF signaling circuit in mediating conditioned taste aversion (CTA) memory extinction of the rats. We found region-specific changes in BDNF gene expression during CTA extinction. CTA extinction led to increased BDNF gene expression in the basolateral amygdala (BLA) and infralimbic prefrontal cortex (IL) but not in the central amygdaloid nucleus (CeA) and hippocampus (HIP). Moreover, blocking BDNF signaling or exogenous microinjection of BDNF into the BLA or IL could disrupt or enhance CTA extinction, which suggested that BDNF signaling in the BLA and IL is necessary and sufficient for CTA extinction. Interestingly, we found that microinjection of BDNF-neutralizing antibody into the BLA could abolish the extinction training-induced BDNF mRNA level increase in the IL, but not vice versa, demonstrating that BDNF signaling is transmitted from the BLA to IL during extinction. Finally, the accelerated extinction learning by infusion of exogenous BDNF in the BLA could also be blocked by IL infusion of BDNF-neutralizing antibody rather than vice versa, indicating that the IL, but not BLA, is the primary action site of BDNF in CTA extinction. Together, these data suggest that BLA-IL circuit regulates CTA memory extinction by identifying BDNF as a key regulator.
\end{abstract}

Key words: basolateral amygdala; brain-derived neurotrophic factor; conditioned taste aversion; extinction; infralimbic prefrontal cortex

\section{Introduction}

Brain derived neurotrophic factor (BDNF), a molecule known to regulate neuronal survival and differentiation, plays a critical role in synaptic plasticity, long-term potentiation (LTP), learning, and memory (Barde et al., 1987; Leibrock et al., 1989; Huang and Reichardt, 2001; Chao, 2003). Much has been reported about BDNF's important role in different memory processes, including acquisition, consolidation, and reconsolidation (Tyler et al., 2002; Rattiner et al., 2004; Lee, 2008; Ma et al., 2011; Wang et al., 2012). Recently, studies have begun to focus on the role of BDNF in memory extinction. Studies have shown that knocking down of BDNF in the dorsal hippocampus or overexpression of

\footnotetext{
Received Dec. 2, 2013; revised April 16, 2014; accepted April 17, 2014

Author contributions: J.X., L.M., and Z.-Y.C. designed research; J.X., L.M., T.-Y.Z., H.Y., Y.W., and L.K. performed research; J.X. and L.M. analyzed data; J.X., L.M., and Z.-Y.C. wrote the paper.

This work was supported by the National 973 Basic Research Program of China (No. 2012CB911000), National Natural Science Foundation of China (No. 31130026, 31371138), the State Program of National Natural Science Foundation of China for Innovative Research Group (No. 81321061), and the Independent Innovation Foundation of Shandong University. We thank X.-F. Zhou (University of South Australia) for providing the rabbit polyclonal antibodies against BDNF.

The authors declare no competing financial interests.

*J.X. and L.M. contributed equally to this work.

Correspondence should be addressed to Dr. Zhe-Yu Chen, Department of Neurobiology, School of Medicine, Shandong University, No.44 Wenhua Xi Road, Jinan, Shandong 250012, P.R. China. E-mail: zheyuchen@sdu.edu.cn. DOI:10.1523/JNEUROSCI.5030-13.2014

Copyright $\odot 2014$ the authors $\quad 0270-6474 / 14 / 347302-12 \$ 15.00 / 0$
}

TrkB.T1 in the basolateral amygdala (BLA) impaired the extinction of fear-potentiated startle (Chhatwal et al., 2006; Heldt et al., 2007). In addition, BDNF Val66Met polymorphism, which is associated with decreased activity-dependent BDNF secretion, led to impaired extinction in mice or human (Egan et al., 2003; Chen et al., 2004; Yu et al., 2009; Soliman et al., 2010). A recent article indicated that the hippocampus (HIP) supplied BDNF into the infralimbic prefrontal cortex (IL) to facilitate contextual fear memory extinction, which indicates the importance of the HIP-IL circuit in mediating BDNF-dependent extinction (Peters et al., 2010). However, how BDNF is transported from the HIP to IL to mediate memory extinction has not been fully understood. Moreover, it remains unclear whether the BDNF neural circuit mediating extinction is consistent across different memory tasks.

Conditioned taste aversion (CTA) is a form of learning where the subject associates a novel taste (termed the conditioned stimulus [CS]) with a subsequent transient visceral illness (termed the unconditioned stimulus [US]), and is an established model for studying the molecular mechanisms of nondeclarative memory in different brain regions. CTA is formed by single-trial training and is a long-lasting memory that provides a useful model for studying the memory extinction. On the basis of the typical CTA paradigm, the neural circuit involved in CTA memory extinction should include the amygdala, ventromedial prefrontal cortex (vmPFC), the parabrachial nucleus, and the nucleus of the soli- 
A

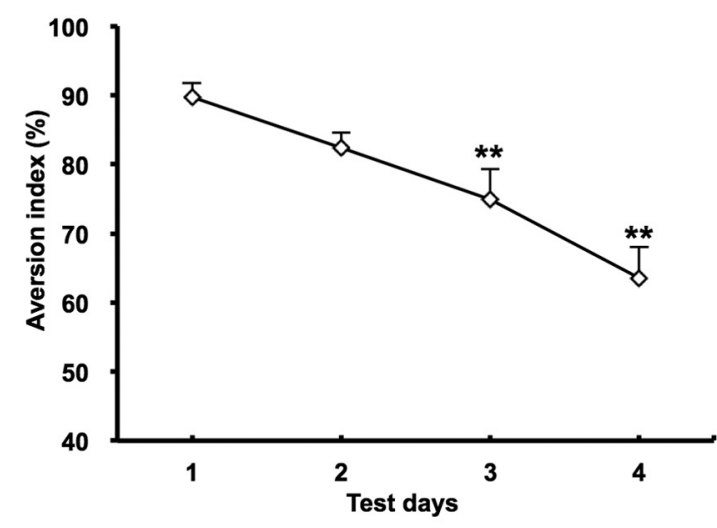

C

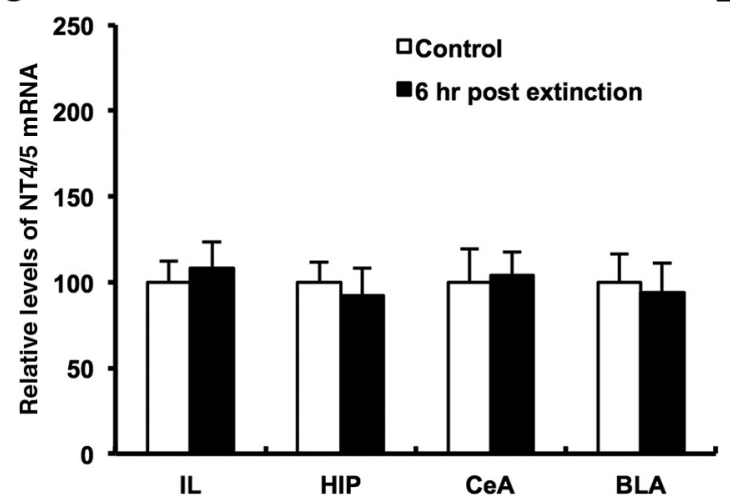

B

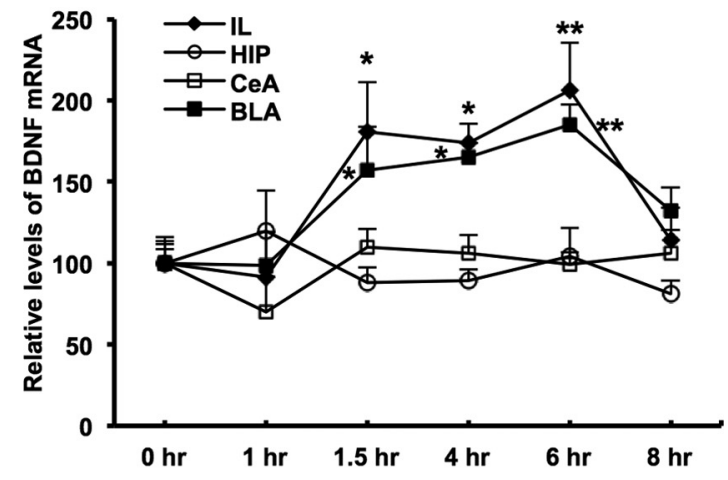

D

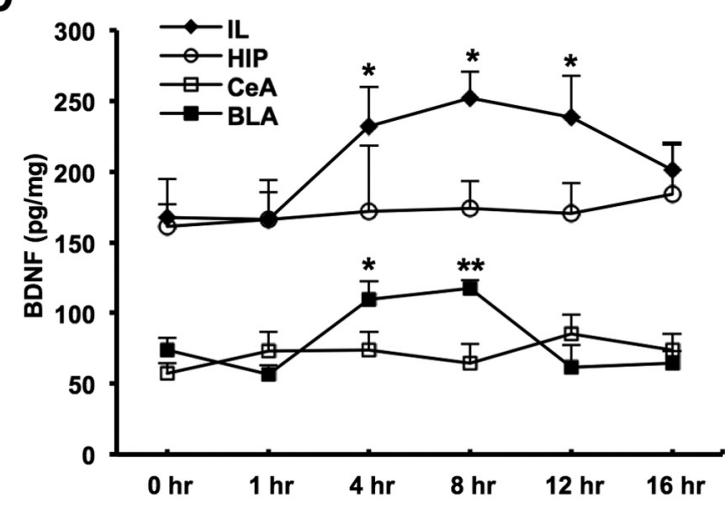

Figure 1. Temporal and spatial regulation of BDNF expression during (TA extinction. $A$, The extinction curve of (TA in rats $\left(n=8\right.$ per extinction trial). ${ }^{* *} p<0.01$, versus the first extinction day (one-way ANOVA). $\boldsymbol{B}$, Temporal and spatial changes of BDNF mRNA levels during (TA extinction using real-time $\mathrm{PCR}\left(n=5\right.$ per time point). ${ }^{*} p<0.05$, versus the values at $0 \mathrm{~h}$ time point (one-way ANOVA). ${ }^{* *} p<0.01$, versus the values at $0 \mathrm{~h}$ time point (one-way ANOVA). C, Levels of NT4/5 mRNA ( $n=6$ per group; one-way ANOVA) do not significantly change at $6 \mathrm{~h}$ after the second (TA extinction test in different brain regions. $D$, Temporal and spatial changes of BDNF protein levels during (TA extinction using ELISA. Rats were killed at $0,1,4,8,12$, or 16 h after the second extinction test, and the BDNF protein levels in the IL, HIP, (eA, and BLA were measured ( $n=5$ or 6 per time point). ${ }^{*} p<0.05$, versus the amount at $0 \mathrm{~h}$ time point (one-way ANOVA). ${ }^{* *} p<0.01$, versus the amount at $0 \mathrm{~h}$ time point (one-way ANOVA).

tary tract (Gallo et al., 1998; Berman et al., 2000; Mickley et al., 2005; Akirav et al., 2006; Yu et al., 2009). In the present study, using CTA paradigm, the involvement of BDNF signaling in CTA extinction on the basis of neural circuit is investigated.

\section{Materials and Methods}

Animals. Wistar rats (2-month-old males, 250-300 g) were individually housed at $22^{\circ} \mathrm{C}$ under $12 / 12 \mathrm{~h}$ light/dark cycles and had access to water and food ad libitum, except when experimental requirements indicated otherwise. All procedures were performed in accordance with the National Institutes of Health Guide for the care and use of laboratory animals and were approved by the institutional animal care and use committee of Shandong University.

Behavioral procedures. The behavioral protocol of CTA was performed following the previous procedures (Desmedt et al., 2003). For the CTA study, saccharin $(0.1 \% \mathrm{w} / \mathrm{v}$, sodium salt $)$ was used as an unfamiliar taste (CS) and intraperitoneal injection of $\mathrm{LiCl}(0.15 \mathrm{M}, 2 \%$ body weight $)$ as the malaise-inducing agent (US). In brief, rats were deprived of water for $24 \mathrm{~h}$, and then they were trained 3-4 $\mathrm{d}$ to obtain their daily water ration within $10 \mathrm{~min}$ from two pipettes, each containing $10 \mathrm{ml}$. On conditioning day, the rats were presented with saccharin instead of water. Forty minutes later, they were injected intraperitoneally with $\mathrm{LiCl}$ solution. On the next $2 \mathrm{~d}$, rats were presented daily for $10 \mathrm{~min}$ with two pipettes containing $10 \mathrm{ml}$ of water each. For extinction, $3 \mathrm{~d}$ after CTA training, rats were presented with a multiple-choice test, three pipettes containing $5 \mathrm{ml}$ of saccharin and three containing $5 \mathrm{ml}$ of water. Conditioned rats preferred water to saccharin at a ratio of 9:1 on their first postconditioning test in this multiple-choice situation. The conditioned rats were pre- sented once a day with the choice situation for 4 consecutive days. The results were quantified by an aversion index $(\mathrm{AI})$, defined as $\mathrm{AI}=[($ milliliters of water $) /($ milliliters of water + milliliters of saccharin $)] \times 100 \%$ consumed in the test.

$q R T-P C R$. For CTA extinction, at least five rats at each time point were killed after the second extinction test. Four different brain regions [IL, HIP, central amygdaloid nucleus (CeA), and BLA] from each rat were dissected out followed by RNA extraction. Total RNA was isolated according to the Ultrapure RNA kit instructions. A $0.5 \mu \mathrm{g}$ aliquot of each sample was treated with DNase to avoid DNA contamination and was then reversely transcribed using the RevertTra Ace qPCR RT Kit (TOYOBO, catalog FSQ-101). Primer sequences were as follows: BDNF forward primer, 5' TAA ATG AAG TTT ATA CAG TAC AGT GGT TCT ACA $3^{\prime}$ and reverse primer, 5' AGT TGT GCG CAA ATG ACT GTT T 3' (Alfonso et al., 2006); NT4/5 forward primer, 5' GAG GCA CTG GCT CTC AGA ATG 3' and reverse primer, 5' CGA ATC CAG CGC CAG C 3' (Harada et al., 2005). The $\beta$-actin was selected as a control (forward, $5^{\prime}$ AGA GGG AAA TCG TGC GTG AC $3^{\prime}$ and reverse, $5^{\prime}$ CAT ACC CAG GAA GGA AGG CT 3'). qRT-PCR was performed in a Cycler (MyiQ2, Bio-Rad) using SYBR green (Takara, DRR041A). The threshold cycle for each sample was chosen from the linear range and converted to a starting quantity by interpolation from a standard curve run on the same plate for each set of primers. Each sample was assayed in duplicate, and the mRNA levels were normalized for each well to the $\beta$-actin mRNA levels using the $2^{-\Delta \Delta \mathrm{Ct}}$ method.

ELISA. At the time of death, the IL, HIP, CeA, and BLA were dissected at various time points after the second extinction test $(n=5$ or 6 per time point) and flash frozen on dry ice, and homogenized. Protein samples 
were used for quantification of total protein and BDNF levels. The ELISA was performed according to the manufacturer's protocol. BDNF levels in each region were assessed using a commercially available assay kit from Promega. In brief, flat-bottom plates were coated with the BDNF capture antibodies. The captured BDNF was bound by a second specific antibody, which was detected using a species-specific antibody conjugated to horseradish peroxidase as a tertiary reactant. All unbound conjugates were removed by subsequent wash steps according to the Promega protocol. Substrate absorbance fluorescence (450 $\mathrm{nm}$ wavelength) was detected and quantified after incubation with chromagenic substrate. All samples were assayed in duplicate.

In situ hybridization. Rats were deeply anesthetized and transcardially perfused with $4 \%$ PFA. Brains were removed and postfixed overnight, then equilibrated at $4^{\circ} \mathrm{C}$ in $30 \%$ sucrose/ $\mathrm{PBS}\left(\mathrm{PO}_{4}{ }^{2-} 0.01 \mathrm{M}, \mathrm{NaCl} 0.15 \mathrm{M}\right.$, $\mathrm{pH}$ 7.4) for at least $3 \mathrm{~d}$ before sectioning. Brains were sectioned on a Microm Cryostat (HM 550, $40 \mu \mathrm{m} /$ section) and stored at $-20^{\circ} \mathrm{C}$.

The in situ hybridization experiments were performed as described previously (Tongiorgi et al., 1998). In brief, after prehybridization, in situ hybridization was performed overnight at $55^{\circ} \mathrm{C}$. After a stringent wash protocol, slices hybridized with DIG-labeled riboprobes were processed for detection with anti-DIG antibodies conjugated with alkaline phosphatase (Roche Diagnostics) for $2 \mathrm{~h}$ at room temperature. Finally sections were incubated in the developing buffer containing nitro blue-terazolium and 5-bromo-4-chloro-3-indolyl-phosphate (Roche Diagnostics). To obtain reproducible and comparable results and to avoid saturation of the reaction, alkaline phosphatase development was always performed for exactly $5 \mathrm{~h}$ at room temperature.

Microphotographs of BDNF mRNA were captured by using a Nikon $80 \mathrm{i}$ light microscope equipped with a charge-coupled device camera interfaced to a personal computer. Illumination was adjusted to obtain optimal staining signal and then was kept constant throughout all experiments. Densitometric analysis was performed on the entire frame observed through the camera under the $20 \times$ objective. The in situ hybridization staining of the control and extinction group was conducted simultaneously under the same experimental condition. The photograph taking and mean density statistics process were performed by two researchers, respectively, in a blind manner such that the researchers had no indication as to the slides from which experiment animal group were taken. Moreover, to eliminate the disturbances effectively by the factors of samples, the threshold value was defined as adjacent background area that lacks hybridization (e.g., callosum). For each section, normalized density $=$ (region of interest density - background density $)$. For statistical analysis, hybridization density is reported as the average density of all individual animals \pm SEM in each experimental group $(n=$ 5). The mean density of all the microphotographs was analyzed with the aid of ImageJ analysis software.

Immunoprecipitation. Rats were killed. Brain tissues were removed and homogenized. Then, the concentration of protein was determined using BCA reagent (Thermo Scientific). For TrkB phosphorylation (p-TrkB) analysis, $5 \mathrm{mg}$ of homogenized lysate was immunoprecipitated using rabbit anti-TrkB antibody (1:100, Millipore), followed by immunoblotting with anti-phospho-tyrosine antibody pY99 (1:4000, Santa Cruz Biotechnology) and mouse anti-TrkB antibody (1:1000, BD Transduction Laboratory), respectively. Ratios of p-TrkB over total TrkB derived from control groups were normalized to 1.0. Values of experimental groups were normalized according to the control group.

Immunohistochemistry. Rats were anesthetized with $10 \%$ chloral hydrate and perfused transcardially with $4 \%$ PFA. Brains were removed and postfixed overnight, then equilibrated at $4^{\circ} \mathrm{C}$ in $30 \%$ sucrose/PBS for $5 \mathrm{~d}$. Brains sections were sectioned on a cryostat microtome (HM 550) at 20 $\mu \mathrm{m}$ and stored at $-20^{\circ} \mathrm{C}$.

The immunohistochemistry histochemistry experiments were performed as follows. Sections on the glass slides were blocked at room temperature in blocking buffer (Tris-buffered saline containing $10 \%$ donkey serum, $0.5 \%$ Triton X-100) for $1 \mathrm{~h}$. After three washes in PBS $(0.1 \mathrm{M}$, $\mathrm{pH}$ 7.4), sections were then incubated with rabbit polyclonal antibodies against BDNF (diluted 1:100 in blocking buffer; provided by Prof. Zhou Laboratory) at $4^{\circ} \mathrm{C}$ overnight. Followed by three washes with PBS, section slides were incubated with donkey anti-rabbit antibody conjugated
A

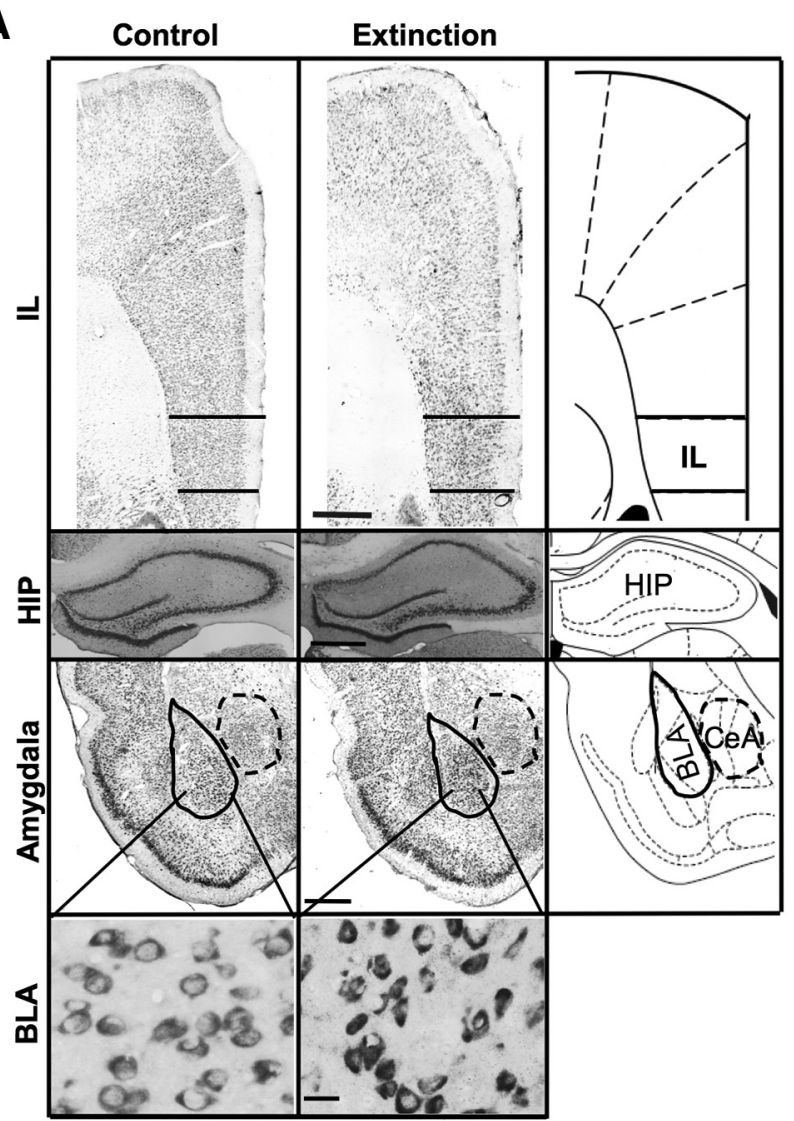

B

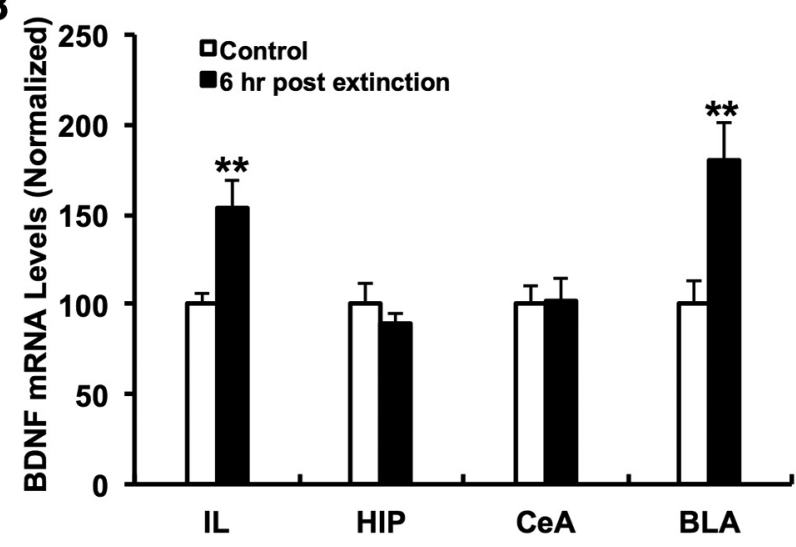

Figure 2. In situ hybridization analysis of regional selective BDNF mRNA changes at $6 \mathrm{~h}$ after the second CTA extinction test. $\boldsymbol{A}$, Representative photomicrographs of coronal rat brain sections from control group or CTA extinction group depicting BDNF mRNA expression in the IL, HIP, CeA, and BLA. Scale bar, $500 \mu \mathrm{m}$. Magnification of sections containing the BLA from control and extinction group are presented at the bottom. Scale bar, $20 \mu \mathrm{m}$. $\boldsymbol{B}$, Quantitative analysis of BDNF mRNA levels from in situ hybridization in the IL, HIP, CeA, and BLA at $6 \mathrm{~h}$ after the second CTA extinction test normalized to control ( $n=5$ per group). ${ }^{* *} p<0.01$ ( $t$ test).

to AlexaFluor-488 (diluted 1:500 in blocking buffer; Invitrogen) at room temperature for $1 \mathrm{~h}$. For each staining trial, slides of both the control and extinction $1 \mathrm{~h}$ groups were conducted simultaneously under the same experimental condition. A blind manner was used during the whole experiments, including the photograph taking. All images were obtained with a Zeiss LSM780 confocal microscope (Microstructural Platform of Shandong University), and all sections of the control and extinction $1 \mathrm{~h}$ groups in one trial had the identical shooting parameters. Images were analyzed using ImageJ analysis software. 
A

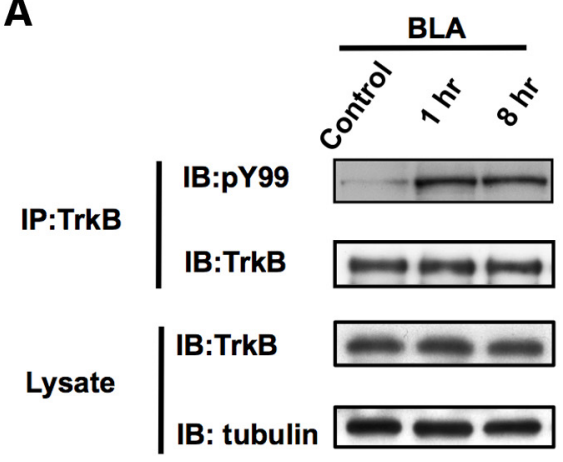

B

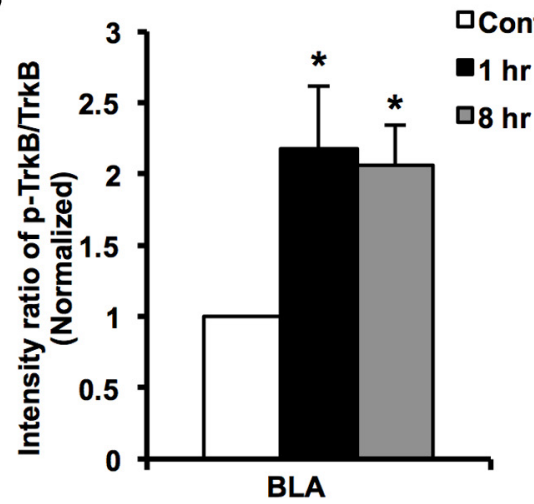

C

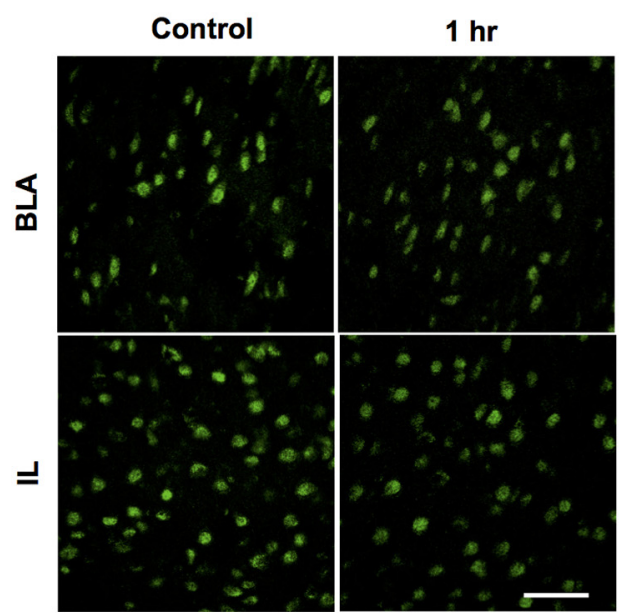

D

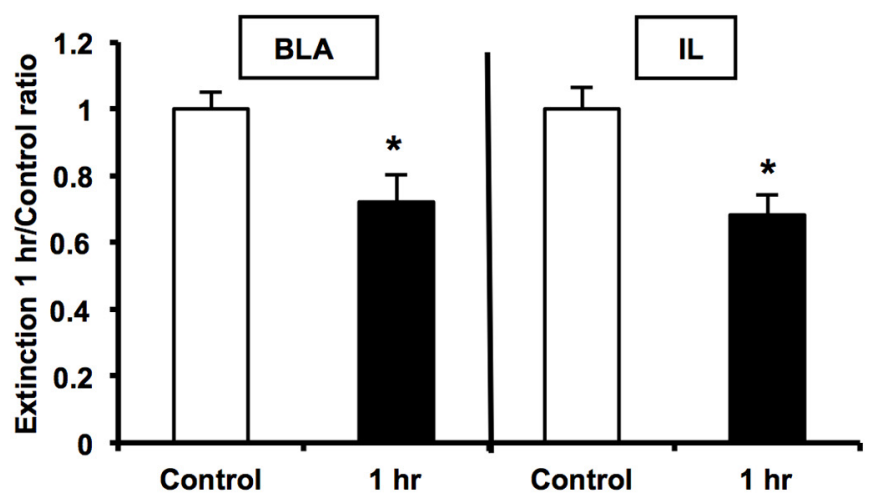

Figure 3. Rapid BDNF secretion-induced TrkB activation in advance of the increased BDNF synthesis. $\boldsymbol{A}, \boldsymbol{B}$, TrkB phosphorylation levels increased in the BLA and IL at both 1 and $8 \mathrm{~h}$ after the second CTA extinction test. $A$, Lysates of BLA and IL were subjected to immunoprecipitation with rabbit anti-TrkB antibodies and immunoblotted with pY99 antibodies (top). Immunoprecipitation of total TrkB was confirmed by immunoblotting with mouse anti-TrkB antibodies (second panel). In addition, TrkB levels from the respective initial lysates were verified by mouse anti-TrkB antibodies (third panel), and $\alpha$-tubulin was used to confirm equivalent
Surgical procedures and drug microinjection. Animals were anesthetized with $10 \%$ chloral hydrate and placed in a stereotaxic apparatus (RWD Life Science, 8001). Animals were each implanted bilaterally with 23 -gauge guide cannula (stainless steel) aimed at $1.0 \mathrm{~mm}$ above the different brain areas following the coordinates below (coordinates in reference to bregma) IL: anteroposterior, $3 \mathrm{~mm}$; lateral, $\pm 0.5 \mathrm{~mm}$; dorsoventral, $-4 \mathrm{~mm}$; BLA: anteroposterior, $-2.58 \mathrm{~mm}$; lateral, $\pm 5 \mathrm{~mm}$; dorsoventral, $-7.4 \mathrm{~mm}$; CeA: anteroposterior, $-2.2 \mathrm{~mm}$; lateral, $\pm 4 \mathrm{~mm}$; dorsoventral, $-7 \mathrm{~mm}$; HIP: anteroposterior, $-3.3 \mathrm{~mm}$; lateral, $\pm 2 \mathrm{~mm}$; dorsoventral, $-3.4 \mathrm{~mm}$ (Paxions and Watson, 1996). The cannulas were positioned in place with acrylic dental cement and secured with skull screws. A stylus was placed in the guide cannula to prevent clogging. Animals were allowed to recover from surgery for a week before experimental manipulations.

For microinfusion, the stylus was removed from the guide cannula, and a 28-gauge infusion cannula (extending $1.0 \mathrm{~mm}$ from the tip of the guide cannula) was inserted. The infusion cannula was connected via PE20 tubing to a microsyringe driven by a microinfusion pump (KD Science, KDS310). K252a (dissolved in ACSF $/ 0.05 \%$ DMSO, $25 \mu \mathrm{M}, 1 \mu \mathrm{l} / \mathrm{side}$, Calbiochem) (Jiang et al., 2001), BDNF antibodies (dissolved in $0.1 \mathrm{~m} \mathrm{PBS}, 1 \mu \mathrm{g} / \mu \mathrm{l}, 0.5 \mu \mathrm{l} / \mathrm{side}$, Millipore Bioscience Research Reagents) (Alonso et al., 2002), human recombinant BDNF (hrBDNF) (prepared in sterile saline, $0.25 \mu \mathrm{g} / \mu \mathrm{l}, 1 \mu \mathrm{l} / \mathrm{side}$, PeproTech) (Bekinschtein et al., 2007), or their respective vehicles were microinfused into different brain regions. To minimize the diffusion scope, the infusion rate was settled as $0.25 \mu \mathrm{l} / \mathrm{min}$. Moreover, after CTA extinction test, microinjection of $1 \mu \mathrm{l}$ methylene blue was performed to confirm the diffused scope, and animals with incorrect diffusion scope were excluded from the data analysis.

Statistical analyses. Data were analyzed with Student's $t$ test, one-way or two-way ANOVA, followed by LSD post hoc comparisons, where appropriate. The significance level was set to 0.05 for all statistical analyses, and all values in the text and figures represent mean \pm SEM.

$\leftarrow$

protein loading (bottom). $\boldsymbol{B}$, Densitometric analyses showing relative levels of $p$-TrkB receptor (in the BLA and IL) relative to total TrkB obtained from immunoprecipitation at 1 and $8 \mathrm{~h}$ after the second CTA extinction test normalized to the control group ( $0 \mathrm{~h}$ after the second extinction test). Error bars indicate SEM. $n=4$ per group. ${ }^{*} p<0.05$, versus control group (one-way ANOVA). C, D, CTA extinction-induced rapid BDNF secretion. C, Representative images of immunofluorescence-stained BDNF in the BLA and IL at 0 or $1 \mathrm{~h}$ after the second CTA extinction test. Scale bar, $50 \mu \mathrm{m}$. D, Relative quantification of the densities of BDNF immunofluorescent staining in the BLA and IL. BDNF levels were significantly decreased in the BLA and IL at $1 \mathrm{~h}$ after the second extinction test compared with the control group. Error bars indicate SEM. $n=5$ per group. ${ }^{*} p<0.05$ ( $t$ test). 


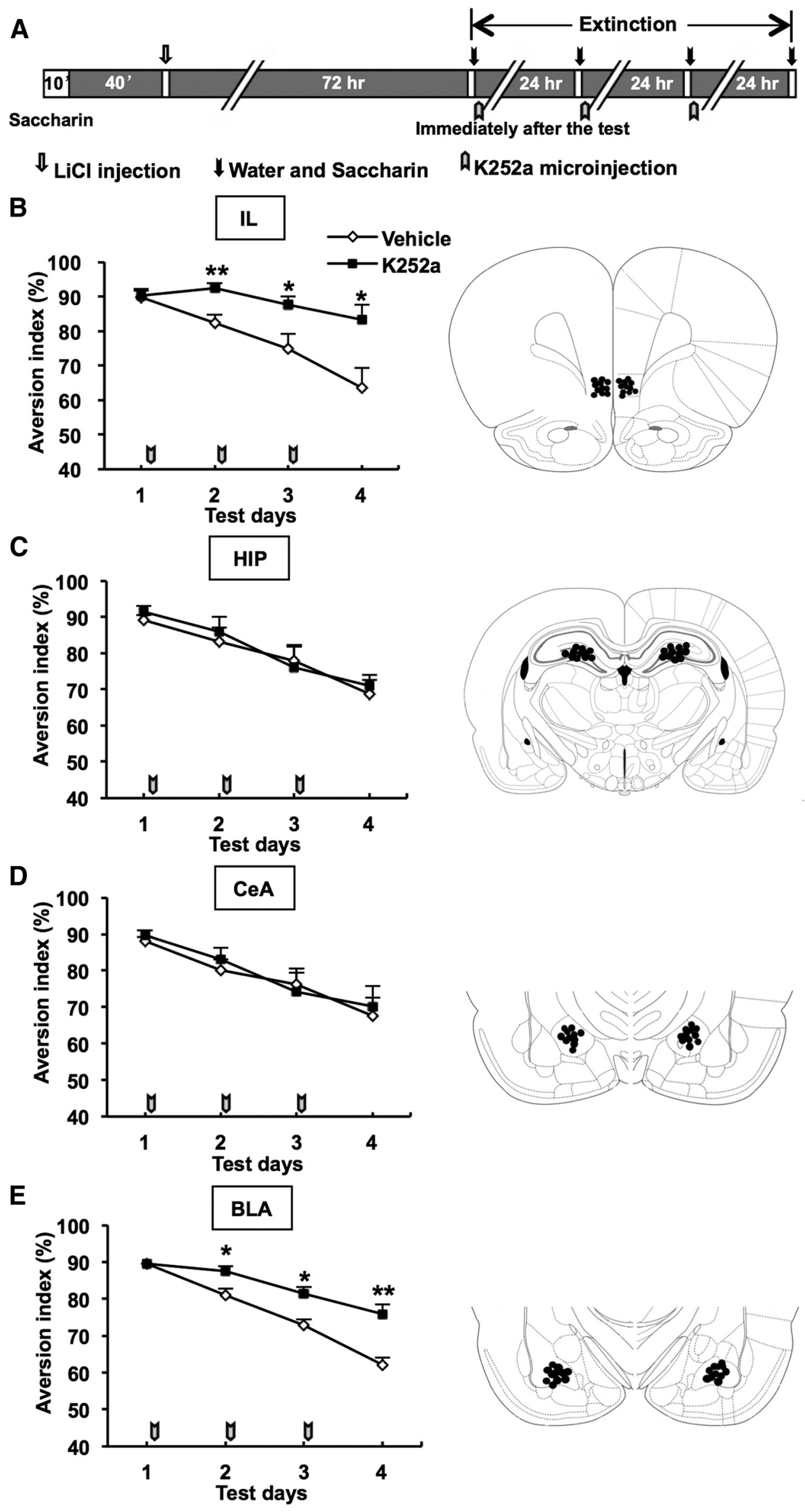


Data analyses were performed using SPSS statistical program version 10.0 .

\section{Results}

\section{Time course of BDNF expression during CTA extinction}

BDNF and its receptor TrkB have been shown to participate in CTA acquisition (Ma et al., 2011). To assess whether the BDNF expression changes in different CTA memory phases follow a similar pattern, we initially examined BDNF expression levels in different brain regions during another CTA process, extinction. First, we found that the aversive levels declined after the third extinction training (Fig. $1 A$; ANOVA: $F_{(3,28)}=10.497, p<0.01$ ), demonstrating the extinction of aversive memory. As the declined aversion index on the third extinction test was caused by the training on the second test day, so the second test day was chosen to detect BDNF mRNA and protein levels changes during CTA extinction. We found that during CTA extinction BDNF mRNA levels increased significantly in the IL (Fig. 1B; ANOVA: $F_{(5,25)}=4.333, p=0.006$ ) and BLA (Fig. $1 B$; ANOVA: $F_{(5,24)}=$ 4.217, $p=0.007$ ) but had no changes in the HIP (Fig. $1 B$; ANOVA: $F_{(5,29)}=1.970, p=0.113$ ) and CeA (Fig. $1 B$; ANOVA: $\left.F_{(5,27)}=1.158, p=0.355\right)$. In Figure $1 B$, BDNF mRNA levels started to increase from $1.5 \mathrm{~h}$ in the BLA and IL and peaked at $6 \mathrm{~h}$; these levels began to return to baseline $8 \mathrm{~h}$ after the second extinction training. To determine whether the expression of other neurotrophin members is also altered during CTA extinction, NT4/5 mRNA levels were measured at $6 \mathrm{~h}$ after the second extinction training. Again, post hoc analysis showed no changes of NT4/5 mRNA levels (Fig. 1C; ANOVA: $F_{(7,40)}=0.177, p=0.989$ ) subsequent to extinction, which indicates the selective induction of BDNF gene expression during CTA extinction.

We next investigated whether the increased BDNF mRNA would lead to BDNF protein levels elevation during CTA extinction. BDNF protein levels were examined using ELISA at 0, 1, 4, 8, 12 , or $16 \mathrm{~h}$ after the second extinction test. Consistent with the changes of BDNF mRNA, increased BDNF protein levels were detected in the IL (Fig. 1D; ANOVA: $F_{(5,28)}=2.984, p<0.05$ ) and BLA (Fig. 1D; ANOVA: $F_{(5,30)}=6.246, p<0.01$ ), but not in the HIP (Fig. $1 D$; ANOVA: $F_{(5,30)}=0.053, p=0.998$ ) or CeA (Fig. $1 D$; ANOVA: $\left.F_{(5,30)}=0.614, p=0.69\right)$. Compared with the time curve of BDNF mRNA level change, BDNF protein levels showed a delayed increase, which started at $4 \mathrm{~h}$ and peaked at $8 \mathrm{~h}$ after extinction training in the BLA and IL, suggesting that the altered protein synthesis occurred in concert with the increases in gene transcription. The increased BDNF protein levels began to return to baseline at $16 \mathrm{~h}$ after extinction training. The temporal change of BDNF expression in the BLA and IL during CTA extinction suggests that BDNF in the BLA and IL may be involved in CTA memory extinction.

To further confirm the changes of BDNF mRNA during extinction, in situ hybridization was performed (Fig. 2A). Consistent with the real-time PCR results, increased BDNF mRNA levels were observed in the IL (Fig. $2 B$; $t$ test, $p<0.01)$ and BLA $(t$

Figure 4. Effects of K252a on CTA extinction. $\boldsymbol{A}$, Schematic of the behavior protocol. Rats received bilateral microinfusion of vehicle or K252a immediately after CTA extinction test, and the extinction tests were performed for 4 consecutive days. $\boldsymbol{B}-\boldsymbol{E}$, Spatial involvement of BDNF/ TrkB signaling in (TA extinction revealed by K252a microinfusion into different brain regions ( $n=8$ per group). ${ }^{*} p<0.05$, versus vehicle group (two-way ANOVA). ${ }^{* *} p<0.01$, versus vehicle group (two-way ANOVA). Arrow indicates the time of drug microinfusion. Cannula placements in the IL, HIP, CeA, and BLA are shown. The schematic anatomical maps are adapted from Paxinos and Watson (2007). test, $p<0.01$ ) in the extinction $6 \mathrm{~h}$ group, with extinction $0 \mathrm{~h}$ group as a control. No noticeable changes were found in the HIP ( $t$ test, $p=0.436)$ or CeA ( $t$ test, $p=0.916$ ). No staining with the BDNF sense probe was detectable in the sections (data not shown). The in situ hybridization results further confirmed region-specific induction of $\mathrm{BDNF}$ gene expression during CTA extinction.

\section{BDNF is secreted in advance of its synthesis during CTA extinction}

To exert its biological effects, BDNF needs to be released from the neuron, bind to its receptor $\operatorname{TrkB}$, and activate downstream signaling pathways (Kaplan and Miller, 2000). p-TrkB levels normalized to total TrkB were examined by immunoprecipitation and immunoblotting upon the second extinction test. We found that $\mathrm{p}$-TrkB levels were significantly higher than that in control group at $8 \mathrm{~h}$ after CTA extinction test in both the BLA (Fig. 3B; ANOVA: $\left.F_{(2,9)}=4.620, p<0.05\right)$ and IL (Fig. 3B; ANOVA: $F_{(2,9)}$ $=5.935, p<0.05)$. Because our previous experiments had shown that BDNF protein levels peaked at $8 \mathrm{~h}$ after the extinction test, the phosphorylation of TrkB was likely triggered by the release of newly synthesized BDNF during the CTA extinction. Interestingly, we found that $\mathrm{p}-$ TrkB levels in the BLA $(p<0.05)$ and IL $(p<0.05)$ were also increased at $1 \mathrm{~h}$ after the extinction test when BDNF protein levels did not show an increase, which indicates CTA extinction training-induced rapid activity-dependent BDNF secretion in advance of the increased BDNF synthesis. To find direct evidence for the secretion of BDNF, we performed the BDNF immunofluorescence histochemistry staining experiments at $1 \mathrm{~h}$ after CTA extinction (Fig. 3C) and measured the fluorescence signaling intensity for BDNF-positive cells in the BLA or IL. Compared with the control group, the values of signaling intensity for BDNF-positive cells in the BLA (Fig.3D; $p<$ $0.05 ; t$ test $)$ and IL $(p<0.05)$ were significantly reduced at $1 \mathrm{~h}$ after the CTA extinction test. Because the BDNF expression levels were not changed at $1 \mathrm{~h}$ after the CTA extinction test, the decrease in BDNF immunostaining intensity is most likely the result of a rapid BDNF release after the CTA extinction. Together, these results suggest that CTA extinction could induce the secretion and synthesis of BDNF.

\section{Blocking BDNF/TrkB signaling in the BLA or IL could impair CTA extinction}

Because our previous results have shown that CTA extinction induced BDNF expression and TrkB phosphorylation, we next investigated whether BDNF is functionally involved in CTA extinction. K252a, a Trk receptor inhibitor, was infused immediately after the extinction test for three consecutive days to measure the specific effect of BDNF on memory extinction (Fig. $4 A)$. Cannula placements in different brain regions are shown in Figure $4 B-E$. When animals received K252a microinfusion into the IL, rats showed a significant delay in the extinction of the aversive memory (Fig. 4B). Two-way ANOVA conducted on aversion index throughout the four extinction days revealed a significant delay (treatment, $F_{(1,63)}=21.293, p<0.01$; test day, $F_{(3,63)}=8.502, p<0.01$; interaction, $\left.F_{(3,63)}=2.595, p=0.061\right)$, and $t$ test showed a significant difference compared with the control group on the second, third, and fourth extinction day ( $t$ test, $p<0.05)$. However, for rats that received K252a infusion into the HIP, there was no effect of treatment (Fig. $4 C$; ANOVA: $F_{(1,10)}=$ $0.135, p=0.716$ ) on CTA extinction compared with the control group. Moreover, we found that inhibition of Trk receptor in the BLA could also block extinction of CTA compared with vehicle- 

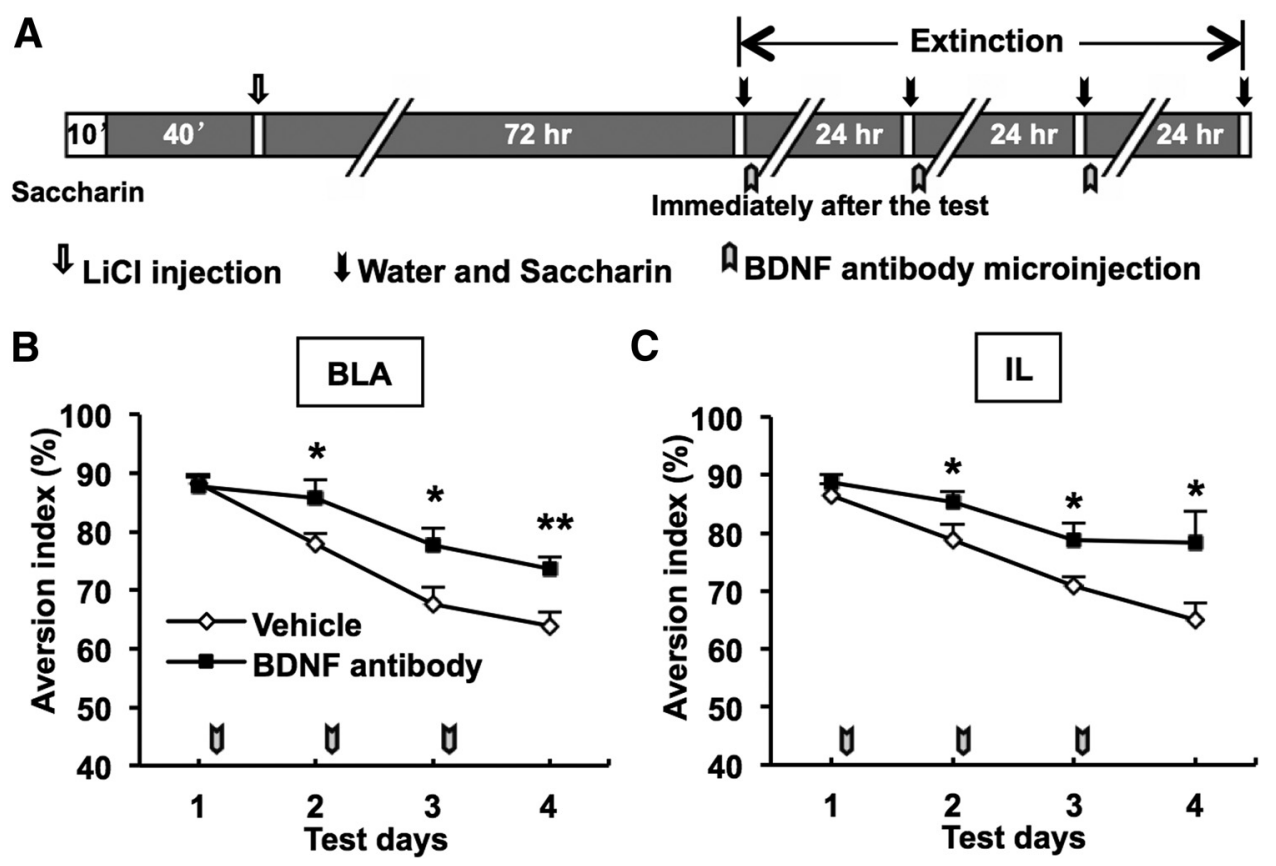

Figure 5. Effects of BDNF-neutralizing antibodies on CTA extinction. $A$, Schematic representation of the behavior protocol. Rats received bilateral microinfusion of BDNF antibodies or vehicles immediately after CTA extinction test, and the extinction tests were performed for 4 consecutive days. $\boldsymbol{B}$, The aversion index during extinction test after infusion of BDNF antibody or vehicle into the BLA ( $n=8$ per group). ${ }^{*} p<0.05$ (two-way ANOVA). ${ }^{* *} p<0.01$ (two-way ANOVA). C, The aversion index during extinction test after infusion of BDNF antibody or vehicle into the IL ( $n=7-10$ per group). ${ }^{*} p<0.05$ (two-way ANOVA). Arrow indicates the time of antibody microinfusion.

treated animals on the next $3 \mathrm{~d}$ after infusion (Fig. $4 E$; treatment, $F_{(1,71)}=18.396, p<0.01$; test day, $F_{(3,71)}=27,935, p<0.01$; interaction, $\left.F_{(3,71)}=2.840, p=0.045\right)$, whereas no effect was found in the CeA (Fig. 4D; ANOVA: $F_{(1,14)}=0.237, p=0.628$ ). Together, these results suggest the functional involvement of BDNF/TrkB signaling in the BLA and IL in CTA extinction, which is consistent with the regional specific BDNF gene expression changes induced by extinction.

Because K252a is an inhibitor of all Trk receptors, to address this further, we microinjected BDNF-neutralizing antibodies into the BLA or IL to observe its effect on CTA extinction (Fig. $5 A)$. We found that infusion of BDNF antibodies into the BLA (Fig. $5 B$; treatment, $F_{(1,56)}=6.257, p<0.05$; test day, $F_{(3,56)}=$ 12.428, $p<0.01$; interaction, $\left.F_{(3,56)}=0.815, p=0.491\right)$ or IL (Fig. $5 C$; treatment, $F_{(1,59)}=11.257, p<0.01$; test day, $F_{(3,59)}=$ 9.922, $p<0.01$; interaction, $\left.F_{(3,59)}=0.964, p=0.415\right)$ immediately after the CTA extinction test delayed CTA extinction compared with control group. This result further confirms that BDNF signaling in the BLA and IL is functionally necessary for CTA extinction.

\section{Exogenous BDNF administration in the BLA or IL could} facilitate CTA extinction

The previous experiments demonstrated that BDNF signaling in the BLA and IL is necessary for CTA extinction. To investigate whether BDNF is sufficient for CTA extinction training, exogenous human recombinant BDNF was microinfused into the BLA or IL immediately after CTA extinction test (Fig. 6A). We found that aversive levels in the BDNF-treated rats were significantly reduced relative to vehicle-infused rats in the BLA group (Fig. $6 B$; treatment, $F_{(1,64)}=7.287, p<0.01$; test day, $F_{(3,64)}=21.553, p<$ 0.01 ; interaction, $F_{(3,64)}=1.013, p=0.393$ ) and IL group (Fig. $6 C$; treatment, $F_{(1,63)}=10.555, p<0.01$; test day, $F_{(3,63)}=$ $27.161, p<0.01$; interaction, $\left.F_{(3,63)}=0.781, p=0.509\right)$, which indicates that BDNF in the BLA and IL is not only necessary but also sufficient for CTA extinction.

\section{BDNF-trigged signaling is transmitted from BLA to IL during} CTA extinction

Our previous results have shown that CTA extinction-induced BDNF expression in the BLA and IL. In addition, anatomical analyses have shown the connections between the BLA and IL (Hoover and Vertes, 2007). We next investigated whether there were any connections between the increased BDNF expression in the BLA and IL during CTA extinction. To address this question, brain tissues were extracted $1.5 \mathrm{~h}$ after BDNF antibodies infused on the second extinction day (Fig. 7A). The extinction $0 \mathrm{~h}$ vehicle group served as a control. Real-time PCR analysis showed that BDNF antibody microinfusion in the BLA (Fig. 7B; BLA, ANOVA: $F_{(2,26)}=7.176, p<0.05$; post hoc: Control vs Extinction + BLA BDNF antibody group, $p<0.05$ ) or IL (Fig. $7 C$; IL, ANOVA: $F_{(2,25)}=3.653, p<0.05$; post hoc: Control vs Extinction + IL BDNF antibody group, $p<0.05$ ) during extinction could block the increased BDNF mRNA levels in the injection site itself, suggesting the local BDNF signaling is necessary for the following local BDNF synthesis. This result is consistent with our previous finding that the phosphorylation of TrkB occurred in advance of BDNF synthesis during the CTA extinction and suggests that the local TrkB phosphorylation is premise for the following BDNF synthesis (Fig. 3). Interestingly, we found that BDNF antibodies microinfusion into the BLA abolished the increased BDNF mRNA levels in the IL at $1.5 \mathrm{~h}$ after CTA extinction test (Fig. $7 B$; IL, ANOVA: $F_{(2,31)}=4.107, p<0.05$; post hoc: Extinction + BLA Vehicle vs Extinction + BLA BDNF antibody group, $p<0.01$ ). However, BDNF antibodies administration into the IL could not inhibit the elevated BDNF expression in the BLA at $1.5 \mathrm{~h}$ after CTA extinction test, and the BDNF mRNA levels in the BLA even showed a trend of compensatory increase (Fig. 7C; BLA, 


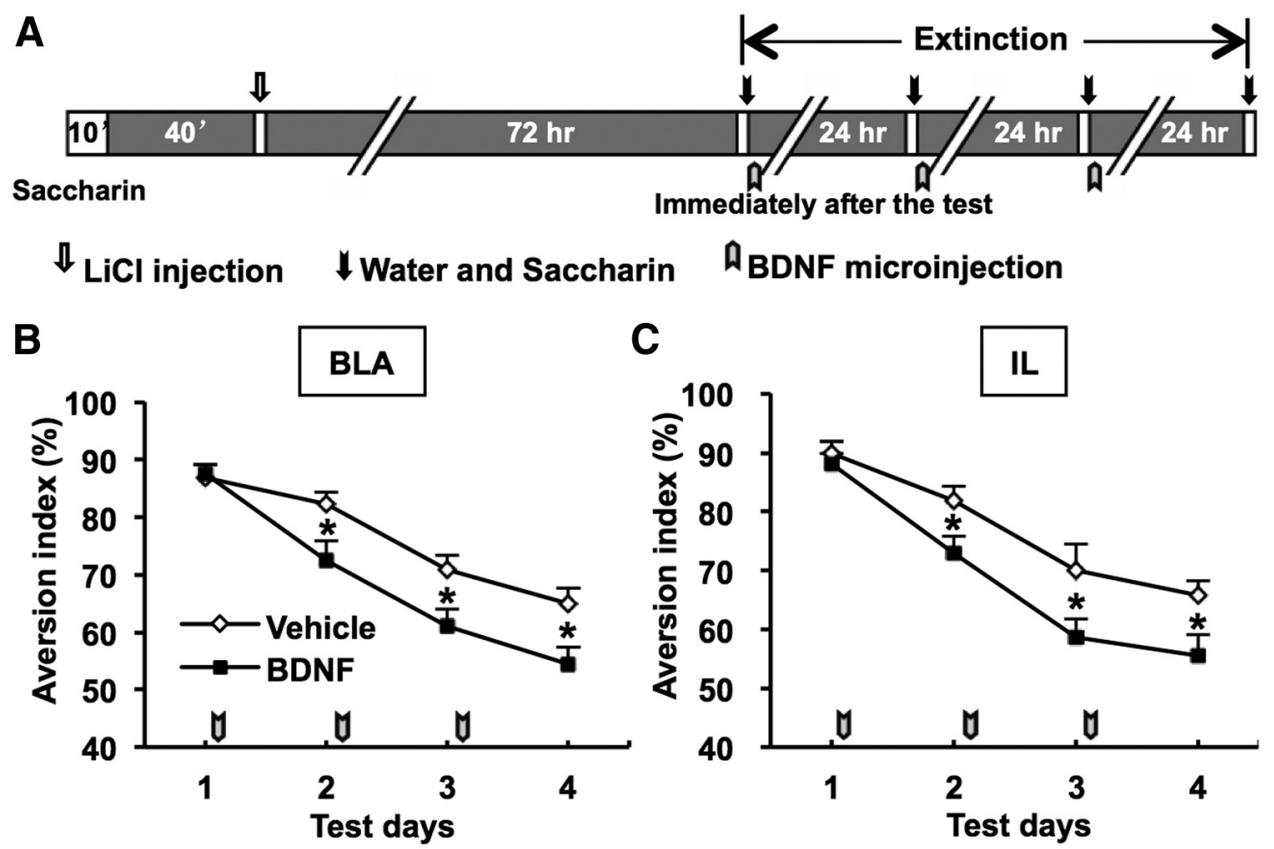

Figure 6. Effects of exogenous BDNF administration on CTA extinction. $A$, Schematic of the behavior protocol. Rats received bilateral microinfusion of vehicle or exogenous BDNF immediately after CTA extinction test, and the extinction tests were performed for 4 consecutive days. $\boldsymbol{B}, \boldsymbol{C}$, Exogenous BDNF infusions into the BLA (B) or IL (C) immediately after the extinction test reduced aversive index relative to the vehicle group ( $n=8$ or 9 per group). ${ }^{*} p<0.05$, versus vehicle group (two-way ANOVA). Arrow indicates time of exogenous BDNF microinfusion.

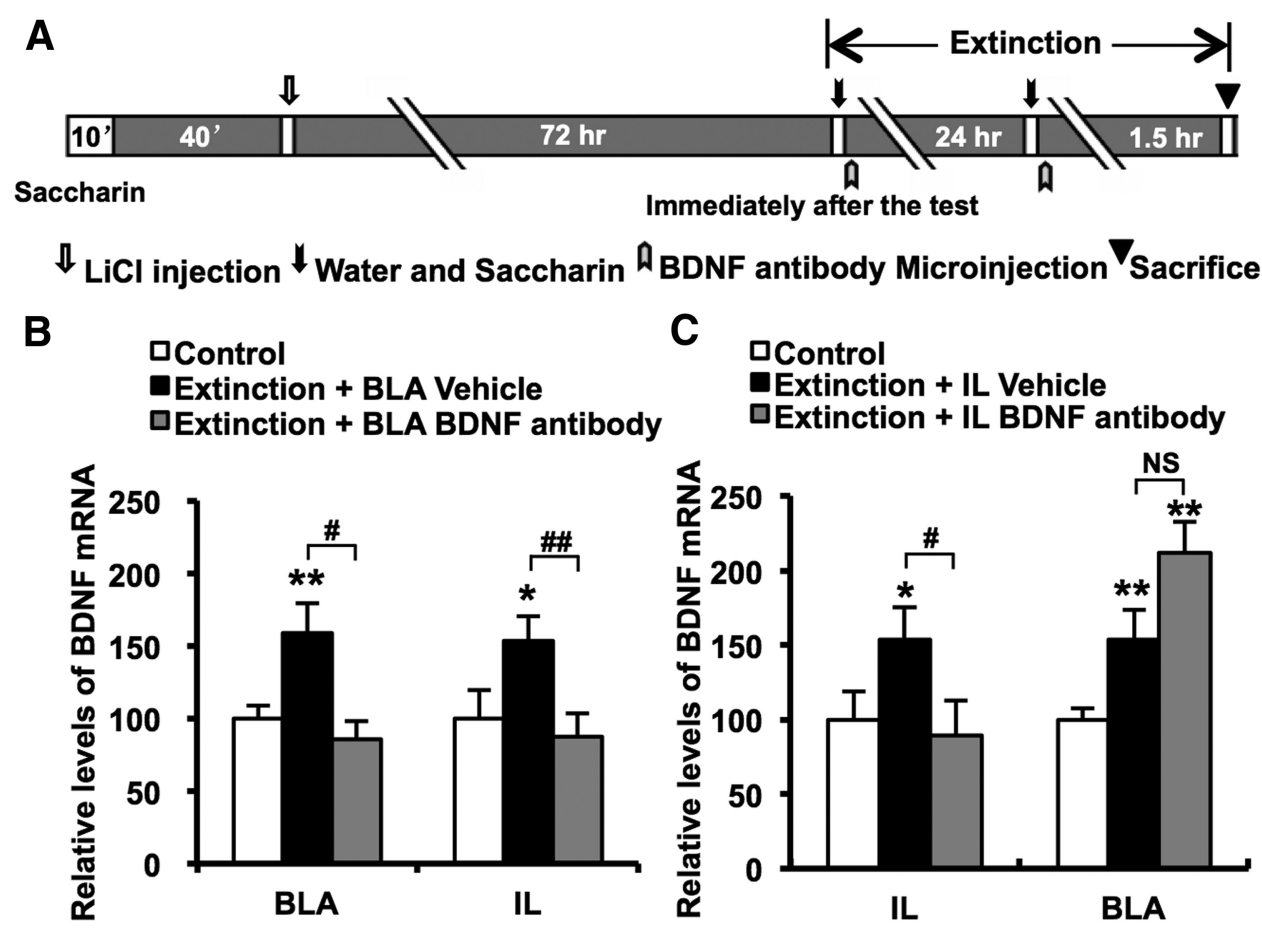

Figure 7. CTA extinction-induced BDNF expression elevation in the IL depends on the BDNF signaling activation in the BLA. $A$, Schematic representation of the behavior protocol. Rats received bilateral microinfusion of BDNF antibodies or vehicles immediately after (TA extinction test, and the extinction tests were performed for 2 consecutive days. All animals were killed at $0 \mathrm{~h}$ or $1.5 \mathrm{~h}$ after the second CTA extinction test. The $0 \mathrm{~h}$ vehicle group served as a control. $B, C$, Real-time PCR analysis showing relative BDNF mRNA expression levels after infusion with BDNF antibodies or vehicle into the BLA (B) or IL ( () at $0 \mathrm{~h}$ or $1.5 \mathrm{~h}$ after the second (TA extinction test normalized to control ( $n=8-12$ per group). ${ }^{*} p<0.05$, compared with the control group (one-way ANOVA). ${ }^{* *} p<0.01$, compared with the control group (one-way ANOVA). ${ }^{\#} p<0.05$, compared with the extinction + vehicle group (one-way ANOVA). ${ }^{\# \#} p<0.01$, compared with the extinction + vehicle group (one-way ANOVA). NS, No significance.

ANOVA: $F_{(2,26)}=11.751, p<0.01$; post hoc: Extinction + IL Vehicle vs Extinction + IL BDNF antibody group, $p=0.262$ ). This result demonstrates that CTA extinction-induced BDNF expression elevation in the IL depends on the BDNF trigged signaling activation in the BLA but not vice versa.
Our above results showed that BDNF trigged signaling was transmitted from BLA to IL during CTA extinction; the next question is how the BDNF signaling is transmitted. To investigate this point, we simulated the effects of secreted BDNF in naive rats. Animals were divided into three groups: BLA Vehicle + IL 
A

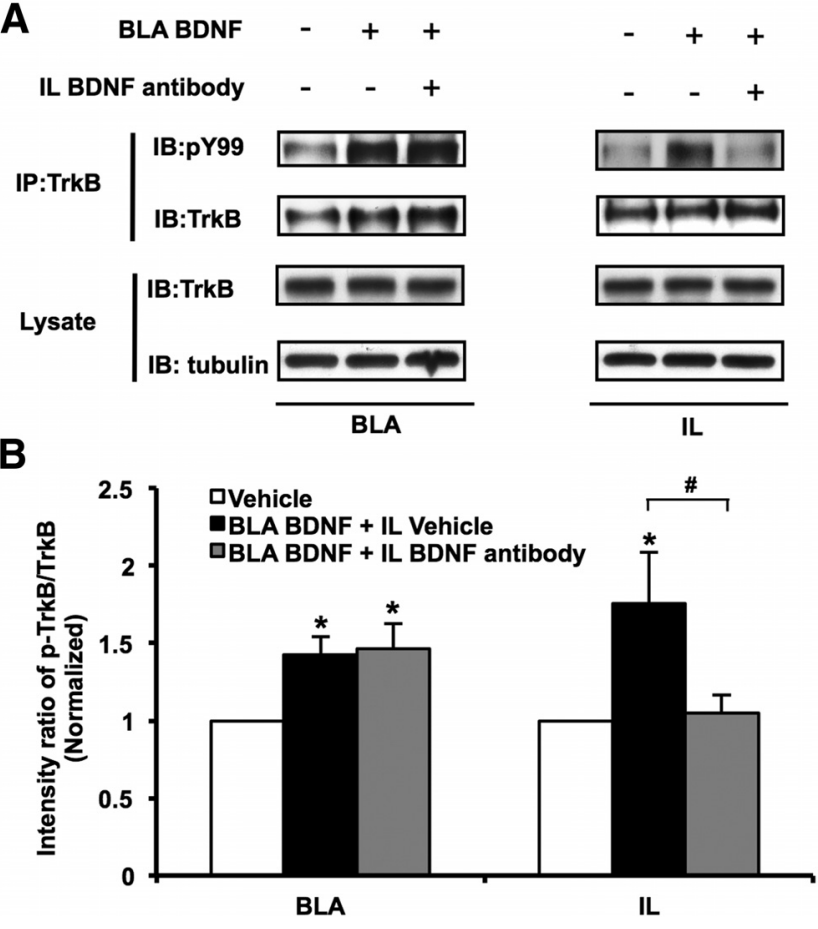

Figure 8. BDNF signaling could be rapidly transmitted from the BLA to IL. $A, B$, Microinfusion of BDNF into the BLA-induced rapid TrkB activation in the IL (within $20 \mathrm{~min}$ ). The increased $\mathrm{p}$-TrkB levels in the IL upon BLA BDNF infusion could be blocked by IL BDNF-neutralizing antibody administration. $\boldsymbol{A}$, Representative immunoblots. $\boldsymbol{B}$, Relative densitometric analysis. The $\mathrm{p}$-TrkB/TrkB ratio is normalized to the vehicle group ( $n=3$ per group). ${ }^{*} p<0.05$, compared with the vehicle group (one-way ANOVA). ${ }^{\#} p<0.05$, compared with the BLA BDNF + IL vehicle group (one-way ANOVA).

Vehicle (Vehicle), BLA BDNF + IL Vehicle, and BLA BDNF + IL BDNF antibody. Not surprisingly, BLA BDNF microinjection could locally activate TrkB in the BLA (Fig. $8 B$; BLA, ANOVA: $F_{(2,7)}=4.781, p<0.05$; post hoc: Vehicle vs BLA BDNF + IL Vehicle, $p<0.05)$. In addition, we also found that $\mathrm{p}$-TrkB levels in the IL were significantly increased at $20 \mathrm{~min}$ after BDNF microinfusion into the BLA compared with vehicle group (Fig. $8 B$; IL, ANOVA: $F_{(2,7)}=4.436, p<0.05$; post hoc: Vehicle vs BLA BDNF + IL Vehicle, $p<0.05$ ), which suggests that BDNF triggered signaling in the BLA can be transmitted into the IL rapidly (within $20 \mathrm{~min}$ ). Within such a short time course, BDNF is not likely to be transported from the BLA to IL. Moreover, we further found that the BLA BDNF microinjection trigged p-TrkB levels increase in the IL could be blocked by IL BDNF antibody microinfusion (Fig. $8 B$; IL, ANOVA: $F_{(2,7)}=4.436, p<0.05$; post hoc: Vehicle vs BLA BDNF + IL BDNF antibody, $p=0.868$ ). As the transported p-TrkB from the BLA should not be blocked by the IL BDNF-neutralizing antibody microinjection, we speculate that the increased p-TrkB levels in the IL on BLA BDNF microinjection are mainly caused by the locally secreted BDNF in the IL.

\section{IL is the primary action site of BDNF mediating CTA extinction}

Because we found the BDNF signaling in the BLA was the input for increased BDNF synthesis in the IL during extinction, next we tried to investigate the primary action site of BDNF during CTA extinction. We put the experience of previous procedures to determine the target structure in mediating BDNF effect on CTA extinction in the BLA-IL circuit (Peters et al., 2010). Rats were divided into the following three groups: one group received a
BLA infusion of BDNF followed by a saline infusion into the IL (BLA BDNF + IL Vehicle); a second group also received a BLA BDNF infusion followed by BDNF-neutralizing antibody infusion into the IL (BLA BDNF + IL BDNF antibody); a control group received saline infusions into both structures (Vehicle) immediately after the CTA extinction test (Fig. 9A). Interestingly, we found that the effect of BLA BDNF microinjection on CTA extinction could be totally reversed by coadministration of BDNF antibody in the IL (Fig. $9 B$; treatment, $F_{(2,115)}=38.854, p<0.01$; test day, $F_{(3,115)}=63.802, p<0.01$; interaction, $F_{(6,108)}=3.828$, $p<0.01$ ), which suggests that the IL may be the primary site of BDNF action mediating CTA extinction. Our previous result showed that CTA extinction could also be facilitated by infusion of BDNF into IL. In an additional experiment, rats received BDNF infusion into IL followed by administration of BDNF antibody into BLA (IL BDNF + BLA BDNF antibody). Compared with the effect of BDNF microinfusion into IL, no significant difference was found in the aversive level after coadministration of BDNF antibody into BLA immediately after the CTA extinction test (Fig. $9 C$; treatment $F_{(2,102)}=13.044, p<0.01$; test day, $F_{3,102)}=68.409, p<0.01$; interaction, $\left.F_{(6,94)}=1.088, p=0.376\right)$. These data suggested that IL is the primary action site of BDNF mediating CTA extinction.

\section{Discussion}

The purpose of this study is to investigate the BDNF signaling circuit in CTA extinction. We provided evidence that BDNF mRNA and protein levels were temporally elevated during CTA extinction in the BLA and IL. Blocking BDNF signaling in the BLA or IL could delay CTA extinction, and exogenous microinjection of BDNF into the BLA or IL enhanced CTA extinction. Moreover, we demonstrated that BDNF signaling was transmitted from the BLA to IL during CTA extinction. Finally, we found the IL was the primary action site of BDNF mediating CTA extinction. We have summarized these results in Figure 10.

Extinction of previously acquired memories is a new form of learning, which leads to the decline in the frequency or intensity of the conditioned response after the withdrawal of reinforcement (Bouton and Nelson, 1994; Myers and Davis, 2002). Previous studies have highlighted the involvement of several structures in CTA extinction, such as vmPFC, BLA, and CeA (Bahar et al., 2003; Akirav et al., 2006; Yu et al., 2009). However, the detailed mechanisms are still unclear. Our data provide several novel insights into the involvement of BDNF neural circuit in mediating CTA extinction. First, we found that BDNF expression was temporally induced in selective brain regions during CTA extinction, whereas levels of other neurotrophins, such as NT4/5, did not change. Elevated BDNF expression levels in the IL and BLA during CTA extinction have been found during CTA extinction, suggesting the possible region-specific involvement of BDNF in CTA extinction. CeA, another subnuclei of amygdala, and HIP had no significant BDNF expression change during CTA extinction, implying that BDNF may play distinct roles in CTA extinction in different brain regions.

Paralleling with the elevated BDNF protein levels, $\mathrm{p}$-TrkB levels were also increased, indicating that these newly synthesized BDNF could activate the downstream signaling to exert biological function. Interestingly, we also found that the TrkB activation-induced by extinction triggered rapid BDNF secretion occurred in advance of the elevated BDNF protein levels. These data suggested that CTA extinction induces BDNF secretion first and activates TrkB and stimulates BDNF synthesis later. More importantly, we found that microinfusion of BDNF antibody 


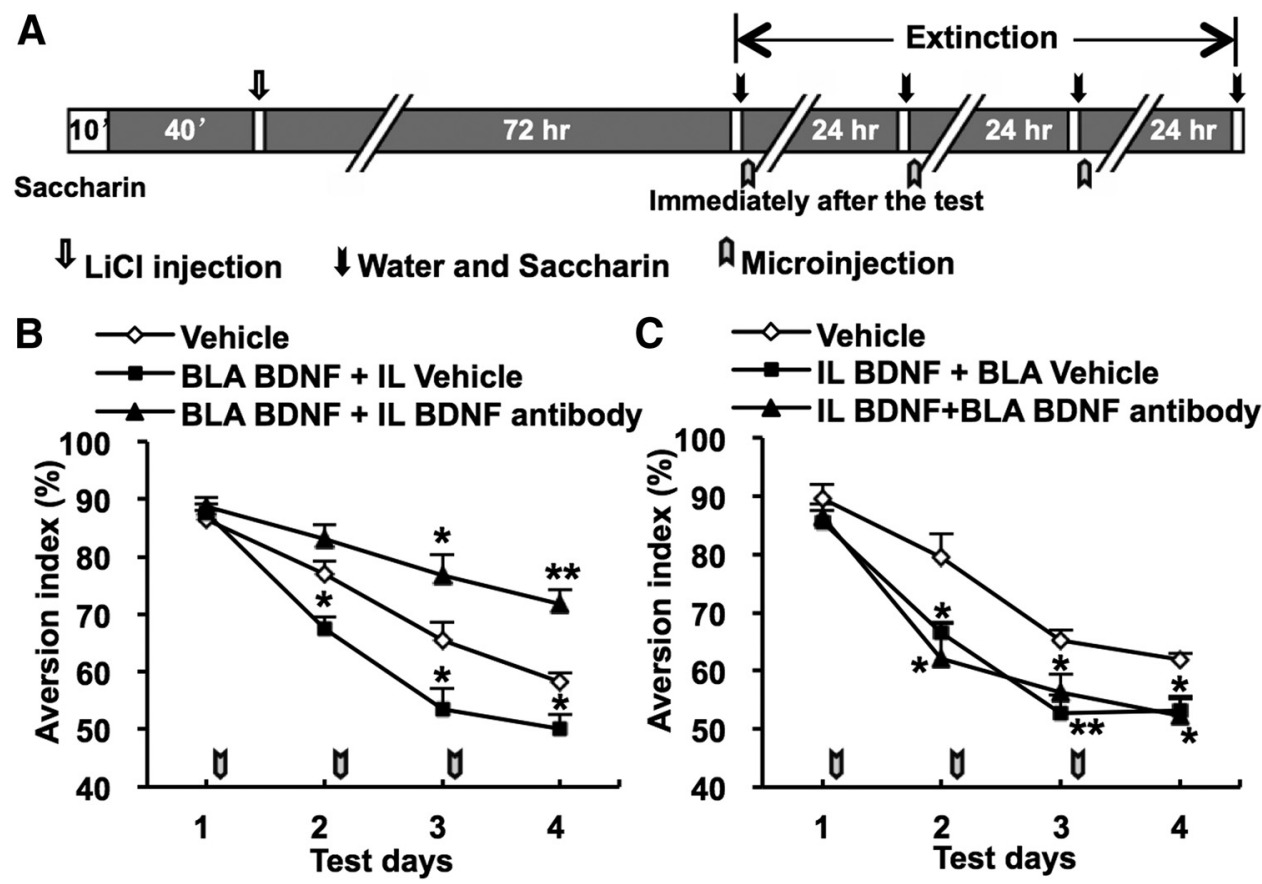

Figure 9. IL is the primary action site of BDNF mediating CTA extinction. $A$, Schematic representation of the behavior protocol. Rats received bilateral microinfusion of BDNF followed by coadministration of BDNF antibody in a separate brain region. $\boldsymbol{B}$, Infusion of BDNF antibody into the IL reversed the BLA BDNF microinfusion-accelerated CTA extinction ( $n=9-12$ per group). ${ }^{*} p<$ 0.05 versus vehicle group (two-way ANOVA). $C$, Infusion of BDNF antibody into the BLA has no effect on the IL BDNF microinfusion-accelerated CTA extinction ( $n=8-10$ per group). ${ }^{*} p<0.05$ versus vehicle group (two-way ANOVA). ${ }^{* *} p<0.01$ versus vehicle group (two-way ANOVA).

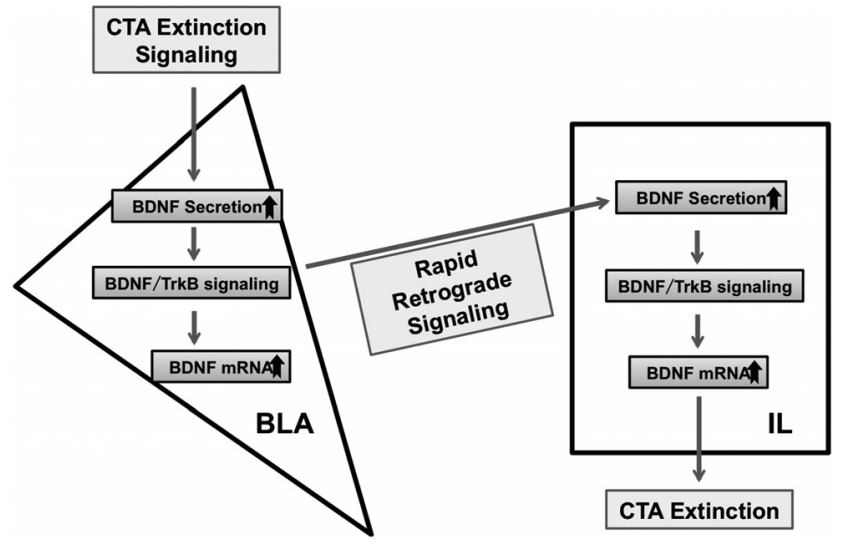

Figure 10. BDNF signaling within BLA-IL circuit mediating CTA extinction. During CTA extinction, BLA receives information that induces the secretion of $B D N F$ and subsequent activation of TrkB and BDNF synthesis. Then the activated TrkB signaling in the BLA is rapidly transmitted to the IL, which triggers BDNF secretion and synthesis in the IL. The BDNF signaling activation in the IL finally mediates CTA extinction.

into the BLA or IL immediately after the extinction test could block the BDNF mRNA levels increase in the injection site itself, indicating that BDNF synthesis is dependent on the initially locally secreted BDNF. Our results suggest that BDNF selfamplifying mechanism involves in CTA extinction, which is consistent with our previous report that the secretion and synthesis of BDNF are spatially and temporally involved in the CTA memory formation (Ma et al., 2011).

Second, we found that BDNF in the BLA and IL was necessary and sufficient for CTA extinction. To date, BDNF has been extensively studied in the hippocampal-dependent memory extinction (Kesslak et al., 1998; Hall et al., 2000). A study has reported that the extinction of fear memory could be significantly im- paired by hippocampus-specific deletion of BDNF in adult mice (Heldt et al., 2007). In addition, it has been shown that overexpressing a dominant-negative TrkB (TrkB.T1) in the BLA to antagonize BDNF signaling could disrupt extinction retention (Chhatwal et al., 2006). However, these studies did not show whether boosting BDNF signaling in the HIP or BLA could facilitate extinction. Moreover, little is known about the role of BDNF in hippocampal-independent cortical memory extinction process. Here, we used CTA model, a hippocampal-independent task, to investigate the effect of BDNF on extinction. Using both loss-of-function (K252a and BDNF-neutralizing antibody administration) and gain-of-function (exogenous BDNF administration) approaches, we found that BDNF signaling in the BLA and IL was not only necessary but also sufficient for CTA extinction, which strengthened the importance of BDNF/TrkB signaling in extinction process across different memory tasks.

Third, this is the first study showing that BDNF signaling was transmitted from the BLA to IL during CTA extinction. Recently, a report has suggested that the enhanced contextual fear extinction by exogenous BDNF microinfusion into the HIP could be prevented by functional blocking BDNF in the IL, which suggests that BDNF activity in HIP-IL circuits involves in the extinction of contextual fear memories (Peters et al., 2010). To our knowledge, this is the first study demonstrating the role of BDNF in memory extinction on the basis of neural circuit. However, it remains unclear how BDNF signaling could be transmitted between different brain regions. Our data suggest the elevated BDNF expression in the IL was triggered by BDNF signaling activation in the BLA during CTA extinction, but not vice versa. This result showed the BDNF signaling connections between these two brain regions during extinction. Next, we simulated the effect of secreted BDNF by application of exogenous BDNF in the BLA to investigate the BDNF signaling propagation mechanism. To our surprise, the increased TrkB activation in the IL was apparent 
within 20 min upon BDNF administration in the BLA. Two models for BDNF retrograde signaling have been proposed. The first one is that the neurotrophins-Trk complex internalizes through clathrin-mediated endocytosis and transported retrogradely to the cell body. This hypothesis has gained considerable support (Halegoua et al., 1991; Yuen et al., 1996; Howe and Mobley, 2004). However, the rate of this transport is $\sim 2.5-7 \mathrm{~mm} / \mathrm{h}$ (Richardson and Riopelle, 1984), which cannot explain the rapid TrkB activation in the IL upon BDNF microinjection into the BLA (within $20 \mathrm{~min}$ ), as the distance from BLA to IL is $\sim 10 \mathrm{~mm}$. On the other hand, it has been reported that NGF-stimulating distal axons of sympathetic neurons could promote neuronal survival without being transported to neuron body (MacInnis and Campenot, 2002), and TrkA activation in cell body could appear long before ${ }^{125}$ I-NGF arrived (Riccio et al., 1997). These studies suggest that the neurotrophic factor does not have to be transported to the cell body to exert its function. So an alternative hypothesis is proposed as Trk retrograde signaling transmission, which is fast but relatively weak to be detected (Ehlers et al., 1995; Bhattacharyya et al., 1997). We found that infusion of BDNF antibody in the IL could block the BLA BDNF administrationinduced increase of $\mathrm{p}$-TrkB in the IL, indicating that the TrkB activation in the IL is more likely to be activated by locally secreted BDNF in the IL rather than the $\mathrm{p}$-TrkB being transported from the BLA to IL. Together, we proposed a model that a rapid but weak Trk signal transmission from BLA to IL during CTA extinction, which then induces local BDNF secretion and TrkB activation in the IL and stimulates the following BDNF synthesis.

Finally, we found that IL was the primary action site of BDNF mediating CTA extinction. As known, there are heavy nerve fiber connections between the IL and the limbic system, such as amygdala, HIP, cingulate cortex, hypothalamus, etc. (Hoover and Vertes, 2007). During the emotional memory extinction, IL could integrate signals afferent inputs from HIP (time and context), amygdala (emotional history of a stimulus), brainstem monoamines (internal state), orbital and lateral PFC (cognitivemnemonic information), and converges them together to determine whether to express extinction or not (Sotres-Bayon and Quirk, 2010). Additionally, amygdala intercalated cell masses receive a strong projection from the IL, and it could be a potentiated IL output to mediate cortical control of amygdala inhibition function (Maren and Quirk, 2004; Paré et al., 2004). We found that BDNF antibody infusion into the IL could reverse the accelerated extinction memory by BDNF infusion into the BLA, but not vice versa. This result suggests that IL was the primary BDNF action site downstream of BLA in mediating CTA extinction. Together with the pervious study (Peters et al., 2010), the contextual and CTA memory extinction may have differential BDNF neural circuit to be involved (HIP-IL or BLA-IL); however, our work identified that BDNF signaling in the IL is essential in memory extinction across different memory tasks. Together, our findings extend the previous finding by identifying BDNF as a key molecule in the IL in memory extinction in distinct neural circuits across different learning tasks.

In conclusion, using the CTA memory paradigm, we determined the spatial-specific changes in BDNF gene expression in CTA memory extinction. We found that BDNF in the BLA and IL was necessary and sufficient for CTA extinction. Finally, we provided evidence that BDNF signaling was transmitted from the BLA to IL during extinction and IL was the primary action site of BDNF in CTA extinction. Our study further extends the understanding of the precise regulation of BDNF in memory extinction on the basis of neural circuit.

\section{References}

Akirav I, Khatsrinov V, Vouimba RM, Merhav M, Ferreira G, Rosenblum K, Maroun M (2006) Extinction of conditioned taste aversion depends on functional protein synthesis but not on NMDA receptor activation in the ventromedial prefrontal cortex. Learn Mem 13:254-258. CrossRef Medline

Alfonso J, Frick LR, Silberman DM, Palumbo ML, Genaro AM, Frasch AC (2006) Regulation of hippocampal gene expression is conserved in two species subjected to different stressors and antidepressant treatments. Biol Psychiatry 59:244-251. CrossRef Medline

Alonso M, Vianna MR, Depino AM, Mello e Souza T, Pereira P, Szapiro G, Viola H, Pitossi F, Izquierdo I, Medina JH (2002) BDNF-triggered events in the rat hippocampus are required for both short- and long-term memory formation. Hippocampus 12:551-560. CrossRef Medline

Bahar A, Samuel A, Hazvi S, Dudai Y (2003) The amygdalar circuit that acquires taste aversion memory differs from the circuit that extinguishes it. Eur J Neurosci 17:1527-1530. CrossRef Medline

Barde YA, Davies AM, Johnson JE, Lindsay RM, Thoenen H (1987) Brain derived neurotrophic factor. Prog Brain Res 71:185-189. CrossRef Medline

Bekinschtein P, Cammarota M, Igaz LM, Bevilaqua LR, Izquierdo I, Medina JH (2007) Persistence of long-term memory storage requires a late protein synthesis- and BDNF-dependent phase in the hippocampus. Neuron 53:261-277. CrossRef Medline

Berman DE, Hazvi S, Neduva V, Dudai Y (2000) The role of identified neurotransmitter systems in the response of insular cortex to unfamiliar taste: activation of ERK1-2 and formation of a memory trace. J Neurosci 20: 7017-7023. Medline

Bhattacharyya A, Watson FL, Bradlee TA, Pomeroy SL, Stiles CD, Segal RA (1997) Trk receptors function as rapid retrograde signal carriers in the adult nervous system. J Neurosci 17:7007-7016. Medline

Bouton ME, Nelson JB (1994) Context-specificity of target versus feature inhibition in a feature-negative discrimination. J Exp Psychol Anim Behav Process 20:51-65. CrossRef Medline

Chao MV (2003) Neurotrophins and their receptors: a convergence point for many signalling pathways. Nat Rev Neurosci 4:299-309. CrossRef Medline

Chen ZY, Patel PD, Sant G, Meng CX, Teng KK, Hempstead BL, Lee FS (2004) Variant brain-derived neurotrophic factor (BDNF) (Met66) alters the intracellular trafficking and activity-dependent secretion of wildtype BDNF in neurosecretory cells and cortical neurons. J Neurosci 24: 4401-4411. CrossRef Medline

Chhatwal JP, Stanek-Rattiner L, Davis M, Ressler KJ (2006) Amygdala BDNF signaling is required for consolidation but not encoding of extinction. Nat Neurosci 9:870-872. CrossRef Medline

Desmedt A, Hazvi S, Dudai Y (2003) Differential pattern of cAMP response element-binding protein activation in the rat brain after conditioned aversion as a function of the associative process engaged: taste versus context association. J Neurosci 23:6102-6110. Medline

Egan MF, Kojima M, Callicott JH, Goldberg TE, Kolachana BS, Bertolino A, Zaitsev E, Gold B, Goldman D, Dean M, Lu B, Weinberger DR (2003) The BDNF val66met polymorphism affects activity-dependent secretion of BDNF and human memory and hippocampal function. Cell 112:257269. CrossRef Medline

Ehlers MD, Kaplan DR, Price DL, Koliatsos VE (1995) NGF-stimulated retrograde transport of trkA in the mammalian nervous system. J Cell Biol 130:149-156. CrossRef Medline

Gallo M, Bielavska E, Roldán G, Bures J (1998) Tetrodotoxin inactivation of the gustatory cortex disrupts the effect of the $N$-methyl-D-aspartate antagonist ketamine on latent inhibition of conditioned taste aversion in rats. Neurosci Lett 240:61-64. CrossRef Medline

Halegoua S, Armstrong RC, Kremer NE (1991) Dissecting the mode of action of a neuronal growth factor. Curr Top Microbiol Immunol 165:119170. Medline

Hall J, Thomas KL, Everitt BJ (2000) Rapid and selective induction of BDNF expression in the hippocampus during contextual learning. Nat Neurosci 3:533-535. CrossRef Medline

Harada C, Harada T, Quah HM, Namekata K, Yoshida K, Ohno S, Tanaka K, Parada LF (2005) Role of neurotrophin-4/5 in neural cell death during retinal development and ischemic retinal injury in vivo. Invest Ophthalmol Vis Sci 46:669-673. CrossRef Medline

Heldt SA, Stanek L, Chhatwal JP, Ressler KJ (2007) Hippocampus-specific 
deletion of BDNF in adult mice impairs spatial memory and extinction of aversive memories. Mol Psychiatry 12:656-670. CrossRef Medline

Hoover WB, Vertes RP (2007) Anatomical analysis of afferent projections to the medial prefrontal cortex in the rat. Brain Struct Funct 212:149-179. CrossRef Medline

Howe CL, Mobley WC (2004) Signaling endosome hypothesis: a cellular mechanism for long distance communication. J Neurobiol 58:207-216. CrossRef Medline

Huang EJ, Reichardt LF (2001) Neurotrophins: roles in neuronal development and function. Annu Rev Neurosci 24:677-736. CrossRef Medline

Jiang B, Akaneya Y, Ohshima M, Ichisaka S, Hata Y, Tsumoto T (2001) Brain-derived neurotrophic factor induces long-lasting potentiation of synaptic transmission in visual cortex in vivo in young rats, but not in the adult. Eur J Neurosci 14:1219-1228. CrossRef Medline

Kaplan DR, Miller FD (2000) Neurotrophin signal transduction in the nervous system. Curr Opin Neurobiol 10:381-391. CrossRef Medline

Kesslak JP, So V, Choi J, Cotman CW, Gomez-Pinilla F (1998) Learning upregulates brain-derived neurotrophic factor messenger ribonucleic acid: a mechanism to facilitate encoding and circuit maintenance? Behav Neurosci 112:1012-1019. CrossRef Medline

Lee JL (2008) Memory reconsolidation mediates the strengthening of memories by additional learning. Nat Neurosci 11:1264-1266. CrossRef Medline

Leibrock J, Lottspeich F, Hohn A, Hofer M, Hengerer B, Masiakowski P, Thoenen H, Barde YA (1989) Molecular cloning and expression of brain-derived neurotrophic factor. Nature 341:149-152. CrossRef Medline

Ma L, Wang DD, Zhang TY, Yu H, Wang Y, Huang SH, Lee FS, Chen ZY (2011) Region-specific involvement of BDNF secretion and synthesis in conditioned taste aversion memory formation. J Neurosci 31:2079-2090. CrossRef Medline

MacInnis BL, Campenot RB (2002) Retrograde support of neuronal survival without retrograde transport of nerve growth factor. Science 295: 1536-1539. CrossRef Medline

Maren S, Quirk GJ (2004) Neuronal signalling of fear memory. Nat Rev Neurosci 5:844-852. CrossRef Medline

Mickley GA, Kenmuir CL, Yocom AM, Wellman JA, Biada JM (2005) A role for prefrontal cortex in the extinction of a conditioned taste aversion. Brain Res 1051:176-182. CrossRef Medline

Myers KM, Davis M (2002) Behavioral and neural analysis of extinction. Neuron 36:567-584. CrossRef Medline
Paré D, Quirk GJ, Ledoux JE (2004) New vistas on amygdala networks in conditioned fear. J Neurophysiol 92:1-9. CrossRef Medline

Paxinos G, Watson C (1996) The rat brain in stereotaxic coordinates, Ed 3. San Diego: Academic.

Peters J, Dieppa-Perea LM, Melendez LM, Quirk GJ (2010) Induction of fear extinction with hippocampal-infralimbic BDNF. Science 328:1288 1290. CrossRef Medline

Rattiner LM, Davis M, Ressler KJ (2004) Differential regulation of brainderived neurotrophic factor transcripts during the consolidation of fear learning. Learn Mem 11:727-731. CrossRef Medline

Riccio A, Pierchala BA, Ciarallo CL, Ginty DD (1997) An NGF-TrkAmediated retrograde signal to transcription factor CREB in sympathetic neurons. Science 277:1097-1100. CrossRef Medline

Richardson PM, Riopelle RJ (1984) Uptake of nerve growth factor along peripheral and spinal axons of primary sensory neurons. J Neurosci 4:1683-1689. Medline

Soliman F, Glatt CE, Bath KG, Levita L, Jones RM, Pattwell SS, Jing D, Tottenham N, Amso D, Somerville LH, Voss HU, Glover G, Ballon DJ, Liston C, Teslovich T, Van Kempen T, Lee FS, Casey BJ (2010) A genetic variant BDNF polymorphism alters extinction learning in both mouse and human. Science 327:863-866. CrossRef Medline

Sotres-Bayon F, Quirk GJ (2010) Prefrontal control of fear: more than just extinction. Curr Opin Neurobiol 20:231-235. CrossRef Medline

Tongiorgi E, Righi M, Cattaneo A (1998) A non-radioactive in situ hybridization method that does not require RNAse-free conditions. J Neurosci Methods 85:129-139. CrossRef Medline

Tyler WJ, Alonso M, Bramham CR, Pozzo-Miller LD (2002) From acquisition to consolidation: on the role of brain-derived neurotrophic factor signaling in hippocampal-dependent learning. Learn Mem 9:224-237. CrossRef Medline

Wang Y, Zhang TY, Xin J, Li T, Yu H, Li N, Chen ZY (2012) Differential involvement of brain-derived neurotrophic factor in reconsolidation and consolidation of conditioned taste aversion memory. PLoS One 7:e49942. CrossRef Medline

Yu H, Wang Y, Pattwell S, Jing D, Liu T, Zhang Y, Bath KG, Lee FS, Chen ZY (2009) Variant BDNF Val66Met polymorphism affects extinction of conditioned aversive memory. J Neurosci 29:4056-4064. CrossRef Medline

Yuen EC, Howe CL, Li Y, Holtzman DM, Mobley WC (1996) Nerve growth factor and the neurotrophic factor hypothesis. Brain Dev 18:362-368. CrossRef Medline 